\title{
Kisspeptin and the control of emotions, mood and reproductive behaviour
}

\author{
Edouard G A Mills', Waljit S Dhillo' and Alexander N Comninos, \\ 1Section of Endocrinology and Investigative Medicine, Imperial College London, Hammersmith Hospital, London, UK \\ 2Department of Endocrinology, Imperial College Healthcare NHS Trust, Hammersmith Hospital, London, UK
}

Correspondence should be addressed to A N Comninos: a.comninos@imperial.ac.uk

\section{Abstract}

Reproduction is fundamental for the survival of all species and requires meticulous synchronisation of a diverse complement of neural, endocrine and related behaviours. The reproductive hormone kisspeptin (encoded by the KISS1/Kiss1 gene) is now a wellestablished orchestrator of reproductive hormones, acting upstream of gonadotrophinreleasing hormone $(\mathrm{GnRH})$ at the apex of the hypothalamic-pituitary-gonadal (HPG) reproductive axis. Beyond the hypothalamus, kisspeptin is also expressed in limbic and paralimbic brain regions, which are areas of the neurobiological network implicated in sexual and emotional behaviours. We are now forming a more comprehensive appreciation of extra-hypothalamic kisspeptin signalling and the complex role of kisspeptin as an upstream mediator of reproductive behaviours, including olfactorydriven partner preference, copulatory behaviour, audition, mood and emotion. An increasing body of research from zebrafish to humans has implicated kisspeptin in the integration of reproductive hormones with an overall positive influence on these reproductive behaviours. In this review, we critically appraise the current literature regarding kisspeptin and its control of reproductive behaviour. Collectively, these data significantly enhance our understanding of the integration of reproductive hormones and behaviour and provide the foundation for kisspeptin-based therapies to treat related disorders of body and mind.

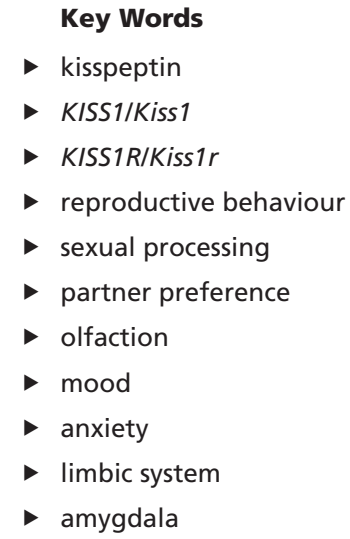

Journal of Endocrinology (2018) 239, R1-R12

\section{Introduction}

The intrinsic links among sex, emotion and reproduction have until recently remained elusive with unclear neural circuits mediating the interactions between physiology, psychology and endocrinology (Yang et al. 2018). Whilst testosterone has traditionally been appreciated as the cardinal factor uniting male reproductive hormones and behaviours, psychosexual function following testosterone replacement in men with idiopathic agerelated hypogonadism remains inferior to age-matched controls despite normalisation of serum testosterone levels (Ramasamy et al. 2015). In addition, testosterone supplementation frequently fails to improve erectile function and libido in eugonadal men (Corona et al. 2014) whilst testosterone replacement therapy in hyperprolactinaemic men fails to restore erectile dysfunction until co-prolactin-lowering therapy is initiated (Carter et al. 1978). Taken together, these observations illustrate that testosterone therapy alone is unable to fully reverse psychosexual dysfunction and suggests the presence of additional factors in human sexual, emotional and reproductive behaviour. To this end, the reproductive hormone kisspeptin is now a well-established orchestrator 
of reproductive physiology with emerging roles in its ability to integrate the hypothalamic-pituitary-gonadal (HPG) reproductive axis with appropriate reproductive behaviours.

In this review, we critically appraise the current literature regarding kisspeptin and its control of reproductive and social behaviour across an assortment of species. English published articles indexed in PubMed were retrieved by means of a series of manual literature searches using the following keywords: kisspeptin, KISS1/Kiss1, KISS1R/Kiss1r, Behaviour, Sex, Reproduction, Olfaction, Partner preference, Audition, Emotion, Mood, Fear, Anxiety, Aggression. Reference lists of selected studies were identified and hand searches were also performed. Searches were conducted up to and including June 2018 to ensure inclusion of the most current data.

As proposed by Gottsch et al., this review adheres to the agreed nomenclature for the key molecules in the kisspeptin signalling pathway: KISS1 and KISS1R denoting kisspeptin and the kisspeptin receptor in humans, and Kiss1 and Kiss1r denoting kisspeptin and the kisspeptin receptor in non-human species, respectively (Gottsch et al. 2009).

\section{Kisspeptin and the kisspeptin receptor}

Kisspeptin, collectively describing the neuropeptides cleaved from its 145-amino acid polypeptide precursor (encoded by the KISS1/Kiss1 gene), is a pivotal regulator of reproductive function. Several isoforms exist with a common RF-amide $\mathrm{C}$ terminus, including kisspeptin (KP)54, KP-14, KP-13 and KP-10 (suffix denoting the number of amino acids) although there is some debate as to what extent each isoform is naturally present (Clements et al. 2001, Kotani et al. 2001). Kisspeptin is the endogenous ligand for the kisspeptin receptor (KISS1R/Kiss1r) (Lee et al. 1999). All of the isoforms have the ability to activate the kisspeptin receptor due to a common C-terminal decapeptide sequence, although KP-54 appears to be the most abundant peptide product in human circulation (Kotani et al. 2001).

Kisspeptin was originally identified as a metastasis suppressor gene (formerly known as metastin) in human melanoma cell lines (Lee et al. 1996). However, landmark studies revealed that KISS1/KISS1R-inactivating mutations in humans or Kiss1r-targeted deletions in transgenic mice, result in a phenotype of delayed puberty and idiopathic hypogonadotropic hypogonadism (de Roux et al. 2003, Seminara et al. 2003, Topalglu et al. 2012). Conversely, activating mutations in KISS1R cause central precocious puberty (Teles et al. 2008). These pivotal observations established the essential role which kisspeptin plays in the timing of puberty and regulation of the HPG axis.

Several seminal studies have developed our understanding of the position kisspeptin plays in the HPG axis. Kisspeptin neurons within the hypothalamus project fibres into the preoptic area, which is rich in gonadotrophin-releasing hormone (GnRH) neurons, with approximately 90-95\% expressing Kiss1r (Han 2005, De Tassigny et al. 2008). These neurons, when stimulated by circulating kisspeptin, release endogenous GnRH, which in turns acts on the anterior pituitary gland leading to gonadotrophin release: luteinising hormone (LH) and follicle-stimulating hormone (FSH) (Messager et al. 2005). This cascade ultimately culminates in the release of sex steroids from the gonads (Hrabovszky 2014). Consistent with this, central and peripheral administration of exogenous kisspeptin stimulates this reproductive cascade in both animals and humans (Thomson et al. 2004, Dhillo et al. 2005). Additionally, administration of a GnRH antagonist abolishes the stimulatory effect of kisspeptin (Gottsch et al. 2004), demonstrating that kisspeptin sits at the apex of the HPG axis. Moreover, in rodents, the arcuate nucleus (ARC) kisspeptin neurons exhibit episodes of synchronised activity, which correlate with pulsatile LH secretion, delineating that these kisspeptin neurons are indeed the hypothalamic GnRH pulse generator (Clarkson et al. 2017). In keeping with this, Clarkson et al. from the Herbison laboratory, also elegantly demonstrated that selective optogenetic activation of ARC kisspeptin neurons generates LH pulses, whereas inhibitory optogenetic strategies result in suppressed LH pulsatility (Clarkson et al. 2017). A possible role for this endogenous rhythmic kisspeptin secretion in behaviour remains to be explored.

The kisspeptin signalling pathway provides an exciting therapeutic target in reproductive hormonal disorders with promising data emerging. Potential therapeutic interventions include stimulating the HPG axis in women with hypothalamic amenorrhea (Jayasena et al. 2009, 2010, 2014a), reversing hyperprolactinaemia-induced ovarian acyclicity (Sonigo et al. 2012) and triggering ovulation in women with infertility (Jayasena et al. $2014 b$ ), including in women at high risk of developing ovarian hyperstimulation syndrome during in vitro fertilisation (Abbara et al. 2015). Given that kisspeptin was initially identified as having anti-metastatic effects, the kisspeptin analogues TAK-448 and TAK-683, have emerged as novel potential therapeutic approaches for 
suppressing testosterone in prostate cancer (MacLean et al. 2014, Matsui et al. 2014). More recent work suggests that kisspeptin-based therapies may also have a role in psychosexual and mood disorders (Comninos \& Dhillo 2017).

\section{Patterns of expression}

\section{Peripheral kisspeptin expression}

In humans, significant kisspeptin expression has been detected in the placenta, pancreas, ovary and liver as demonstrated by quantitative reverse transcriptasepolymerase chain reaction analysis (Muir et al. 2001, Ohtaki et al. 2001, Gaytán et al. 2009). In addition to these aforementioned sites, notable kisspeptin receptor expression has also been identified in the heart and skeletal muscle through northern blot analysis (Clements et al. 2001, Muir et al. 2001, Ohtaki et al. 2001, Gaytán et al. 2009).

\section{Central kisspeptin expression}

Our knowledge of the distribution of kisspeptin signalling within the central nervous system has been mapped extensively, providing functional clues as to its roles in different aspects of neuroendocrine function as below.

\section{Hypothalamic expression}

Kisspeptin has been localised in two major neuronal populations within the hypothalamus of rodents, as demonstrated by in situ hybridisation: the ARC and the rostral periventricular region of the third ventricle (RP3V) (Gottsch et al. 2004, Clarkson et al. 2009, Mikkelsen \& Simonneaux 2009). Kisspeptin neurons within the rodent RP3V are sexually dimorphic with a femaledominant preponderance (Clarkson \& Herbison 2006). Furthermore, in certain short-lived female rodents such as the Siberian hamster, in summer photoperiods, kisspeptin is highly expressed in the RP3V, with low expression in the ARC, whereas a marked reversal occurs during winter photoperiods (Mason et al. 2007). This therefore provides an insight into the ability of hypothalamic kisspeptin neurons to relay reproductively relevant stimuli to the HPG axis in order to support reproduction during favourable environmental conditions.

In human hypothalamic tissues collected at postmortem from premenopausal and postmenopausal women, kisspeptin neurons are located predominantly in the infundibular nucleus (equivalent to the rodent ARC), with a significant postmenopausal increase in both neuronal size and number (Rometo et al. 2007). Further studies demonstrate a sexual dimorphism with significantly more kisspeptin fibres in the infundibular nucleus and rostral preoptic area in women compared to men (Hrabovszky et al. 2010).

\section{Extra-hypothalamic expression}

Significant kisspeptin expression has been demonstrated in key limbic and paralimbic brain regions. In humans, kisspeptin and kisspeptin receptor expression has been localised in the medial amygdala (MeA), cingulate, globus pallidus, hippocampus, medial frontal gyrus, accumbens, parahippocampal gyrus, putamen and thalamus (Kotani et al. 2001, Muir et al. 2001). In rodents, kisspeptin neurons and receptors reside in regions including the MeA, hippocampus, striatum and thalamus (Lee et al. 1999, Clarkson et al. 2009, Herbison et al. 2010, Kim et al. 2011, Pineda et al. 2017).

Kisspeptin expression in the rodent MeA is sexually dimorphic with higher levels in adult males than females in dioestrus (Kim et al. 2011). This is postulated to be accounted for by sex differences in circulating androgens, with the posterodorsal nucleus of the medial amygdala (MePD) having a greater volume in male rodents than females, which shrinks to female size following castration (Cooke et al. 1999). Interestingly, MeA kisspeptin expression varies in relation to the oestrous cycle and peaks at proestrus but is still lower than that in male rodents (Kim et al. 2011).

Examining the functional role of kisspeptin signalling within the amygdala, a recent study employed manganese-enhanced MRI to map neuronal activity within the amygdala of rodents in response to kisspeptin administration (Comninos et al. 2016). Peripheral kisspeptin administration results in a modulation of signal intensity in the amygdala, with associated simultaneous increases in circulating LH. Furthermore, direct intramedial amygdala administration of kisspeptin stimulates LH secretion, whilst conversely intra-medial amygdala administration of a kisspeptin antagonist decreases $\mathrm{LH}$ secretion and pulsatility (Comninos et al. 2016). This provides evidence that extra-hypothalamic kisspeptin signalling, specifically within the amygdala, modulates HPG reproductive hormone secretion.

Using fluorescence immunohistochemistry, a recent rodent study has provided further mechanistic data regarding amygdala kisspeptin neurons, identifying that they receive vasopressinergic and dopaminergic neuronal 
inputs, which may serve as putative mediators (Pineda et al. 2017). This is of functional relevance, as it suggests interplay with key behavioural neuropeptides, implicated in social behaviour and motivational control (MeyerLindenberg et al. 2011).

The discovery that kisspeptin signalling is present in limbic brain regions such as the amygdala of rodents and humans (Lee et al. 1999, Kotani et al. 2001, Muir et al. 2001, Clarkson et al. 2009), which are areas of the neurobiological network implicated in sexual and emotional behaviours (Lehman et al. 1980, Murray 2007) lends credence to the hypothesis that the kisspeptin system may modulate these functions. The resulting studies are detailed below and summarised in Table 1.

\section{Kisspeptin and reproductive behaviour}

Reproduction is fundamental for the survival of each species and requires meticulous synchronisation of a diverse complement of neural, endocrine and related behaviours. The overriding objective is to ensure that mating occurs with the optimal partner at the most appropriate time and place (Hull et al. 2006). Aided by an increasing number of studies, we are now beginning to appreciate that as well as being the chief regulator of the HPG axis, kisspeptin also plays a crucial role in the control of reproductive behaviours.

\section{Olfaction}

Sensory stimuli play a major role in the modulation of social and emotional behaviours, as well as the development of interpersonal relationships. One key modality is olfaction (Vandenbergh 2006). The olfactory bulb, comprising the main and the accessory olfactory systems, is a pivotal region of the vertebrate forebrain (including in humans) involved in the detection of olfactory cues. This includes pheromones, which are species- and gender-specific chemical factors, involved in orchestrating sexual and social behaviour (Dulac \& Torello 2003). The rodent main olfactory system originates at the main olfactory epithelium (MOE), whilst the accessory olfactory system includes the vomeronasal organ (VNO) and the accessory olfactory bulb (AOB) (Meisami \& Bhatnagar 1998).

Kisspeptin neurons in the rodent RP3V are activated by male (but not female) urinary odours in female mice (Bakker et al. 2010). Congruous to this, increased kisspeptin expression (measured by c-Fos-immunopositive Kiss1-expressing cells) in the RP3V of female rats also occurs in response to male-soiled bedding but not when exposed to clean or female-soiled bedding (Watanabe et al. 2017). Furthermore, this increased kisspeptin expression on exposure to male odours induces an enhanced LH surge (Watanabe et al. 2017), providing functional relevance by demonstrating that kisspeptin can integrate olfactory cues with the HPG axis.

The precise olfactory input pathway to the RP3V kisspeptin neurons in female rodents has only recently emerged as demonstrated by selective ablation of the VNO (by surgical resection) and/or the MOE (by intranasal infusion with zinc sulphate solution) (Hellier et al. 2018). Using c-Fos as a marker of kisspeptin neuronal activation, removal of the VNO (but not ablation of the MOE), completely eliminates the ability of male odours to activate the RP3V kisspeptin neurons (Hellier et al. 2018). This therefore delineates that the olfactory input pathway to the RP3V kisspeptin neurons occurs via the VNO in rodents.

Examining the rodent anatomical pathways in further detail, using retrograde and anterograde tracer microinjections, reciprocal connectivity between the $\mathrm{AOB}$ and amygdala kisspeptin neurons has been identified (Pineda et al. 2017). In addition, amygdala kisspeptin neurons also project to GnRH neurons in the preoptic area, as demonstrated by double immunofluorescence histochemistry (Pineda et al. 2017). This study therefore provides evidence for a neural circuit through which amygdala kisspeptin neurons integrate olfactory cues with the HPG axis in rodents. Evidence suggests that kisspeptin signalling is also crucial in behavioural responses to olfactory cues, specifically olfactory partner preference, as detailed in the next section (summarised in Table 1).

\section{Partner preference}

An obligate to reproductive success in mammalian species is the establishment of partner preference leading to mating with the opposite sex. As discussed in the previous section, olfactory cues, especially species- and genderspecific pheromones, trigger sexual signals between potential partners (Dulac \& Torello 2003). Kisspeptin signalling has emerged as pivotal in modulating sexual partner preference.

Gonadally intact testosterone-replaced male Kiss1rknockout mice fail to display an olfactory partner preference despite normosmia, as evidenced by spending a comparable amount of investigatory time with male and female mice (Kauffman et al. 2007). This demonstrates that 
Table 1 Summary of the established role of kisspeptin (KP) in the control of reproductive behaviour in $\mathrm{H}$ (humans), R (rodents) and Z (zebrafish).

\begin{tabular}{|c|c|}
\hline Reproductive behaviour & Functions of kisspeptin \\
\hline Olfaction & $\begin{array}{l}\text { - Olfactory input to RP3V KP neurons via VNO in female R (Hellier et al. 2018) } \\
\text { - Reciprocal connectivity between AOB and amygdala KP neurons, the latter also projecting to } \\
\text { POA GnRH neurons, in male R (Pineda et al. 2017) } \\
\text { - Only male odours activate RP3V KP neurons in female R (Bakker et al. 2010) } \\
\text { - Only male odours activate RP3V KP neurons in female R, resulting in LH surge } \\
\text { (Watanabe et al. 2017) }\end{array}$ \\
\hline Partner preference & $\begin{array}{l}\text { - Kiss1r essential in male R (Kauffman et al. 2007) } \\
\text { - Enhanced by MePD KP neuronal activation in male R (Adekunbi et al. 2018) } \\
\text { - Kiss1, Kiss1r and GnRH signalling required in female R (Hellier et al. 2018) }\end{array}$ \\
\hline Audition & - ARC KP neurons activated in response to male USVs in female R (Asaba et al. 2017) \\
\hline $\begin{array}{l}\text { Female reproductive } \\
\text { behaviour }\end{array}$ & $\begin{array}{l}\text { - RP3V KP neurons essential for lordosis in female R (Hellier et al. 2018) } \\
\text { - Lordosis is dependent on NO signalling, but independent of GnRH and Kiss } 1 r \text { signalling in } \\
\text { female R (Hellier et al. 2018) }\end{array}$ \\
\hline Male reproductive behaviour & $\begin{array}{l}\text { - Kiss1r KO in male } \mathrm{R} \text { results in reduced mounting, thrusting and intromitting but these } \\
\text { behaviours restored by testosterone replacement (Kauffman et al. 2007) } \\
\text { - MePD KP administration induces ex copula erections in male R (Gresham et al. 2016) }\end{array}$ \\
\hline Sexual processing & $\begin{array}{l}\text { - } \mathrm{KP} \text { administration enhances limbic and paralimbic brain activity on fMRI specifically in } \\
\text { response to sexual and bonding images in male } \mathrm{H} \text { (Comninos et al. 2017) }\end{array}$ \\
\hline Social behaviour & $\begin{array}{l}\text { - KP administration has antidepressant effects in male R (Tanaka et al. 2013) } \\
\text { - KP administration has antidepressant effects in male H (Comninos et al. 2017) } \\
\text { - KP administration reduces fear in male Z (Ogawa et al. 2014) } \\
\text { - KP signalling reduces (Adekunbi et al. 2018) or induces (Csabafi et al. 2013, Delmas et al. 2018) } \\
\text { anxiety in male R } \\
\text { - KP administration enhances limbic and paralimbic brain activity in response to sexual images, } \\
\text { which correlates with reduced sexual aversion in male H (Comninos et al. 2017) }\end{array}$ \\
\hline
\end{tabular}

$\mathrm{AOB}$, accessory olfactory bulb; fMRI, functional magnetic resonance imaging; GnRH, gonadotrophin releasing hormone; LH, luteinising hormone; MePD, posterodorsal nucleus of the medial amygdala; NO, nitric oxide; POA, preoptic area; RP3V, rostral periventricular area of the third ventricle; USVs, ultrasonic vocalisations; VNO, vomeronasal organ.

an intact kisspeptin receptor signalling system is critical for olfactory-based male partner preference. Whether a similar observation occurs in female Kiss1r-knockout mice is currently unknown.

In close agreement with this, a recent study employed the pharmacosynthetic DREADDs (designer receptors exclusively activated by designer drugs) technique to selectively activate kisspeptin neurons in the MePD of male mice (Adekunbi et al. 2018). This study identified that DREADD-induced activation of MePD kisspeptin neurons leads to a significant enhancement in partner preference as evidenced by a preference score more than double that during control (Adekunbi et al. 2018). This demonstrates an integral role for the MePD kisspeptin neurons in partner preference.

Recent data have emerged about a similar critical role of kisspeptin signalling in female rodent partner preference. Ovariectomised and hormone-replaced (with oestrogen and progesterone) female Kiss1-knockout mice fail to display a male-directed partner preference during a three compartment box test with the female test mouse in the central compartment and an intact male and an oestrous female in the lateral compartments (Hellier et al.
2018). However, a single peripheral injection of kisspeptin restores a strong male preference, as demonstrated by more time spent by the female test mouse poking her nose through or sniffing the partition holes in front of the male stimulus over a 10-min observation period. Viral ablation of the RP3V kisspeptin neurons (by bilateral stereotaxic injections into the RP3V with an adenoassociated virus encoding a Cre recombinase-dependent caspase) results in Cre+ females also failing to display any male-directed preference. This behavioural deficit, however, resolves following a single peripheral injection of kisspeptin (Hellier et al. 2018), therefore confirming the key role of RP3V kisspeptin signalling in female rodent partner preference.

To determine if the role of kisspeptin in partner preference is dependent on downstream GnRH, a mouse line, GnRH:: Cre; Dicer loxp/loxp, in which mice display a phenotype characterised by progressive loss of GnRH synthesis and secretion postnatally (Messina et al. 2016), has been used to investigate this further. These mice fail to show a male-directed preference, which resolves following a single peripheral injection of GnRH, but not kisspeptin (Hellier et al. 2018). This implies that in 
addition to kisspeptin, GnRH signalling is necessary for mate preference in female rodents.

Collectively, these studies highlight that kisspeptin plays a critical role in modulating partner preference in both male and female rodents (summarised in Table 1). Specifically, kisspeptin signalling in the MePD of male mice and the RP3V of female mice have so far been shown to have key roles, with further studies required to identify possible sexual dimorphism.

\section{Audition}

Many mating rituals include vocal communication as a key component. The effect of male mice emitting songlike 'ultrasonic vocalisations (USVs)' in order to facilitate sexual approach and the impact that this has on female kisspeptin neuron activity has been recently studied (Asaba et al. 2017). In this study, kisspeptin neuronal activation was assessed using dual-label immunocytochemistry for kisspeptin and cAMP response element-binding protein phosphorylation (pCREB). The number of kisspeptin neurons in the ARC expressing pCREB significantly increases following exposure to USVs of male mice compared with control noise, and this correlates with the time spent by a female seeking the male emitting USVs (Asaba et al. 2017), providing behavioural functional relevance. This observation therefore outlines a functional pathway by which kisspeptin signalling is able to mediate auditory cues to activate reproductive function and behaviour. More work is necessary to examine the effects of USVs on downstream reproductive hormones.

\section{Female reproductive behaviour}

As detailed in previous sections, olfactory and auditory cues stimulate neurobiological circuits making it possible to recognise opposite-sex conspecifics. This facilitates a range of reproductive behaviours, which act as important precursors to reproduction. In non-primate female mammals, male tactile stimuli lead to the female adopting a lordosis posture, crucial for reproductive success, characterised by ventral arching of the spine and elevation of the hips to facilitate penile penetration (Kow et al. 2007).

Both ovariectomised female Kiss1-knockout mice and female mice who receive a stereotaxic injection to acutely ablate RP3V kisspeptin neurons fail to display normal lordosis behaviour despite oestrogen and progesterone replacement (Hellier et al. 2018). However, in both cases, this deficit normalises following a single peripheral injection of kisspeptin. Furthermore, optogenetic activation of RP3V kisspeptin neurons results in robust kisspeptin neuron firing and provokes a lordosis response (Hellier et al. 2018). Together, these observations from this seminal study illustrate the vital role of kisspeptin in governing the key copulatory behaviour of lordosis in female mice.

By contrast, when ovariectomised Kiss $1 r$-knockout mice are hormone replaced (with oestrogen and progesterone), they display normal female sexual behaviour, including lordosis (Kauffman et al. 2007). This implies that the kisspeptin receptor (unlike kisspeptin) is not essential for normal female sexual behaviour but adequate sex steroid replacement is. As kisspeptin can act through neuropeptide FF receptors to modulate neuronal activity, which is independent of Kiss $1 r$ in rodents (Liu \& Herbison 2015); this suggests that kisspeptin may also act on other receptors for the control of lordosis behaviour.

In order to dissect the lordosis circuitry downstream of kisspeptin neurons, GnRH:: Cre; Dicer ${ }^{\text {loxp/loxp }}$ (oestrogen and progesterone replaced), where mice are unable to synthesise and secrete GnRH in adulthood display unaffected lordosis behaviour (Hellier et al. 2018). This indicates that in contrast to the previously detailed dependence on GnRH for kisspeptin-mediated olfactory partner preference, kisspeptin-mediated lordosis is not dependent on GnRH signalling.

In keeping with the data that lordosis behaviour is not dependent on downstream GnRH signalling, alternative neurotransmitters have been investigated, including nitric oxide (NO). Neuronal nitric oxide synthase (nNOS)knockout female mice fail to display lordosis behaviour (Hellier et al. 2018). However, whilst a peripheral injection of a NO donor restores lordosis behaviour in nNOSknockout mice, a peripheral injection of kisspeptin or GnRH does not (Hellier et al. 2018). This implicates the mechanism controlling lordosis behaviour as dependent on nitric oxide signalling, acting downstream of kisspeptin neurons. Congruous to this, NOS neurons in the preoptic region express kisspeptin receptors and NO release is required for the kisspeptin-dependent preovulatory action of GnRH neurons (Hanchate et al. 2012). Collectively, these observations establish that interactions between kisspeptin and downstream NO governs lordosis behaviour in rodents and also has a role in reproductive hormone secretion via GnRH.

Taken together, these findings validate a crucial role for kisspeptin signalling in governing the key copulatory behaviour of lordosis in female mice (summarised in Table 1). Specifically, data establishes that 
kisspeptin-mediated lordosis behaviour is independent of GnRH signalling but dependent on downstream NO signalling.

\section{Male reproductive behaviour}

Similar to females, male reproductive behaviours act as important precursors to reproduction. In most mammals, olfactory cues trigger an assortment of reproductive behaviours, including sexual arousal, erections, pelvic thrusts, intromission and ejaculation.

Male Kiss1r-knockout mice fail to display male sexual behaviour, as illustrated by a failure to mount, thrust or ejaculate (Kauffman et al. 2007). However, testosterone replacement rescues this with these mice displaying robust male sexual behaviour comparable to wild-types in terms of mounting, thrusting and intromissions. Intriguingly, the proportion of males ejaculating is lower in testosterone-replaced Kiss1r-knockout mice compared with wild-types, despite more thrusting bouts. However, this is likely attributable to incomplete penile development in Kiss1r-knockout mice (Kauffman et al. 2007). These findings suggest that the kisspeptin receptors is important but not essential for certain male rodent reproductive behaviours.

Examining the influence of key limbic brain regions in more detail, direct infusion of kisspeptin into the MePD of male rats, induces multiple ex-copula erections, once a dose threshold for kisspeptin is reached (Gresham et al. 2016). Conversely, co-administration of a kisspeptin receptor antagonist blocks this erectile response to kisspeptin. Additionally, infusion of kisspeptin into the lateral cerebral ventricle fails to evoke erections suggesting site specificity for the aforementioned effects in the MePD. Furthermore, the observation that LH increased comparably after both direct MePD and intracerebroventricular kisspeptin administration, but erections only occurred after MePD administration, suggests that the mechanism whereby MePD kisspeptin administration triggers erections is LH (and presumably GnRH) independent. These findings indicate that kisspeptin via action on its cognate receptor, specifically in the MePD, can trigger ex-copular erections in rats (Gresham et al. 2016). The exact mechanism downstream of the kisspeptin receptor driving the erectile response is currently unclear and may occur via the interplay with other neurotransmitter systems.

Other male reproductive behaviours mediated by the amygdala have also been assessed. When adult male mice receive bilateral MePD stereotaxic injections of a
DREADD viral construct, comparable levels of copulatory behaviour (mounting, intromission and ejaculation) are observed in the presence and absence of MePD kisspeptin neuronal activation (Adekunbi et al. 2018). This implies that MePD kisspeptin neurons may play a limited role in these reproductive behaviours in male mice in this model (Adekunbi et al. 2018). The influence of kisspeptin in other limbic brain regions and interplay with other neurotransmitter systems when modulating male reproductive behaviour awaits further delineation.

\section{Sexual processing}

A recent study provided the first in human data for the role of kisspeptin in sexual and emotional brain processing by means of a randomised, double-blinded, two-way crossover, placebo-controlled study in 29 healthy heterosexual young men (Comninos etal. 2017). The limbic system was activated using validated themed picture tasks during a functional MRI scan (including sexual, non-sexual couple bonding, negative and neutral pictures). Peripheral administration of kisspeptin enhances limbic brain activity specifically in response to sexual and bonding images. Furthermore, this enhancement correlates with behavioural measures of reward, drive and reduced sexual aversion providing key functional relevance. Notably, these observations occur without any changes in other hormones, which are known to influence limbic brain activity, including testosterone, oxytocin and cortisol (Comninos et al. 2017). These findings are highly relevant when considering the therapeutic role, which kisspeptin could play in the management of sexual and emotional clinical disorders.

\section{Kisspeptin and social behaviour}

Successful reproduction is influenced by social behaviours, such as mood, fear and anxiety. Recent data reveal that kisspeptin also plays an integral role in the regulation of these social behaviours relevant to reproduction in the studies detailed below.

\section{Mood and emotion}

A temporal relationship between mood and reproduction exists, with negative mood impairing reproductive success (Lakatos et al. 2017). In male rodents, dose-dependent antidepressant-like effects of kisspeptin are observed when administered by intracerebroventricular injection during a modified forced swimming test, as signified by 
significantly decreased immobility, but increased climbing and increased swimming times (Tanaka et al. 2013). Pretreatment with an alpha-adrenergic receptor antagonist (phenoxybenzamine or yohimbine) or a non-selective 5-HT2 serotonergic receptor antagonist (cyproheptadine), blocks these effects. This suggests that kisspeptin signalling has antidepressant-like effects in rodents mediated by alpha-adrenergic and 5-HT2 serotonergic systems (Tanaka et al. 2013).

The antidepressant effects of kisspeptin in rodents raise the possibility that similar benefits occur in humans. In the previously mentioned functional neuroimaging study in men, peripheral kisspeptin administration enhances frontal brain activity (critical in regulating human negative mood regulation) in response to negative pictures (Comninos et al. 2017). Furthermore and in keeping with the aforementioned rodent study, kisspeptin administration reduces negative mood (Comninos et al. 2017). Together, these findings have important implications when considering the potential therapeutic role of kisspeptin-based therapies in psychosexual and mood disorders (summarised in Table 1).

\section{Fear}

Fear is an established mediator of impaired reproductive function (Kongsted 2004) and the role of kisspeptin in modulating fear in fish has been studied. Notably, the kisspeptin system displays diversity between different fish species, including variations in the anatomical setup of kisspeptin neurons (Tena-Sempere et al. 2012). In zebrafish, two kisspeptin genes exist: kiss1 with neurons expressed in the ventromedial habenula and kiss2 neurons located in the hypothalamic nucleus, which serves as the principal gonadotrophin regulator (Kitahashi et al. 2009). However, differences exist concerning which of the kisspeptin genes is responsible for producing the hypophysiotropic response in different fish species (Tena-Sempere et al. 2012). During an odorant-cue alarm substance (AS)-induced fear response in male zebrafish, kiss1 and serotoninrelated genes are significantly reduced, whilst kisspeptin administration attenuates this fear response (Ogawa et al. 2014). Specifically, this AS-evoked fear response is mediated by 5-HT1A and 5-HT2 subtype receptors (Nathan et al. 2015). Thus, interactions between kisspeptin and the serotonin system appear to play a central role in modulation of fear in zebrafish and the previously mentioned antidepressant effects in rodents (summarised in Table 1).

\section{Anxiety}

The interaction between anxiety and reproductive success is well recognised (Lakatos et al. 2017). Both acute and chronic stress-induced plasma corticosterone results in downregulation of hypothalamic kisspeptin signalling in rodents (Kinsey-Jones et al. 2009), suggesting interplay between kisspeptin and hypothalamic-pituitary-adrenal (HPA) pathway. The effects of kisspeptin on the HPA axis, motor behaviour and thermoregulatory function have been investigated by administering intracerebroventricular kisspeptin in rodents (Csabafi et al. 2013). This results in stimulation of the HPA axis with significant elevations in basal corticosterone levels, as well as marked spontaneous locomotor activity and induction of hyperthermia, attributable to anxiety (Csabafi et al. 2013). By contrast, intraperitoneal injection of kisspeptin does not alter basal or stress-induced axis activity in adult male rats (Rao et al. 2011). This implies that whilst some of the behavioural effects of kisspeptin may be mediated via interplay with other endocrine pathways, such as the HPA axis, that differences between central and peripheral administration may also exist.

Gonadal steroids are recognised for playing an important role in regulating anxiety-related behaviour in rodents (Chen et al. 2014). However, undertaking experiments in Kiss1r-knockout or gonadectomised mice, results in absent gonadal steroids. In a recent rodent study of anxiety-related behaviour, to ensure normal levels of circulating testosterone in Kiss1r-deleted male mice, Kiss1r in GnRH neurons was selectively rescued (Delmas et al. 2018). Using this methodology, mice spend twice as much time in the open arms of an elevated plus maze compared to controls, suggesting kisspeptin signalling is vital for anxiogenic neural circuits in response to fear of heights (Delmas et al. 2018).

In contrast, selective activation of kisspeptin neurons in the MePD of adult male mice by bilateral stereotaxic injections of a DREADD viral construct results in significantly increased social interaction times (Adekunbi et al. 2018). This manifests as a longer exploratory time in the open arms of an elevated plus maze (Adekunbi et al. 2018), suggestive of a decreased anxiety response. In humans, peripheral administration of kisspeptin has no observed effect on anxiety (Comninos et al. 2017).

Together, these studies indicate that the links between kisspeptin and anxiety require further elucidation, particularly when considering the therapeutic role of kisspeptin-based therapies (summarised in Table 1). Currently species and methodological differences result 
in anxiogenic (Csabafi et al. 2013, Delmas et al. 2018), anxiolytic (Adekunbi et al. 2018) or no anxiety effects (Thomson et al. 2004, Comninos et al. 2017) by kisspeptin signalling.

\section{Aggression}

Territorial and aggressive behaviours are evolutionary displays, commonly related to competition over mating opportunities and thus govern reproductive success (Lindenfors \& Tullberg 2011). The effects of kisspeptin on associated territorial and aggressive behaviours, in both a laboratory and field setting, in the side-blotched male lizard has been examined (Neuman-Lee et al. 2017). Although kisspeptin treatment significantly affects circulating testosterone concentrations as expected, it does not alter aggressive behaviours, when compared to vehicle. However, individuals displaying greater elevations in circulating testosterone, also display more territorial behaviour, as evidenced by pushups (Neuman-Lee et al. 2017). This therefore implies an indirect kisspeptin effect on aggressive behaviour via activation of the HPG axis and downstream testosterone release. Investigating whether kisspeptin has direct (non-testosterone mediated) effects on territorial and aggressive behaviours remains an area of future research.

\section{Discussion and future directions}

Sex, emotion and reproduction are critical aspects of mammalian behaviour that have evolved to guarantee successful reproduction. It is widely established that kisspeptin plays a pivotal role in the physiology of the HPG axis (de Roux et al. 2003, Seminara et al. 2003, Clarkson et al. 2017). However, until recently, the role of kisspeptin signalling outside of the hypothalamus was largely unknown. The observation that kisspeptin and its cognate receptor are present in limbic brain structures, which are areas implicated in social and emotional behaviour, has triggered several studies examining whether kisspeptin is capable of integrating these neural circuits with the modulation of GnRH and gonadotropin release. Furthermore, this is an important future direction for the kisspeptin field (Lehman et al. 2018).

We are now forming a more comprehensive appreciation of kisspeptin signalling beyond the hypothalamus and the complex role of kisspeptin as an upstream regulator of reproductive behaviour. An increasing body of research from zebrafish to humans has implicated kisspeptin in the integration of reproductive hormones with the positive aspects of reproductive behaviours (summarised in Table 1). Such areas include olfactory-driven partner preference, copulatory behaviour, audition, fear, anxiety and sexual aversion. Emerging data suggest further interplay between kisspeptin and other key behavioural neuropeptides systems, which are implicated in social behaviour, such as serotoninergic, vasopressinergic, dopaminergic, adrenergic and nitric oxide systems.

Advances in neuroimaging and molecular techniques, have offered and continue to offer a unique opportunity to understand the intricacies of kisspeptin and reproductive behaviour in more detail. Future areas of interest will include the effects of kisspeptin on other functions and explorations of potential sexual dimorphism in various species. To date, studies have been performed in male and female rodents, male zebrafish, male lizards and men (summarised in Table 1). However, the roles of kisspeptin on the same behaviours have often not been assessed in the opposite sex emphasising a need for studies to address potential sex differences. Furthermore, delineating the precise pathways for these behaviours will provide further foundations for the therapeutic use of kisspeptin-based therapies. These and other studies are warranted to develop our understanding of reproductive biology and ultimately develop kisspeptin as a therapeutic for reproductive and behavioural disorders in the clinic.

\section{Declaration of interest}

The authors declare that there is no conflict of interest that could be perceived as prejudicing the impartiality of this review.

\section{Funding}

The Section of Endocrinology and Investigative Medicine is funded by grants from the MRC, BBSRC, NIHR, an Integrative Mammalian Biology Capacity Building Award, and FP7-HEALTH-2009-241592 EuroCHIP grant and is supported by the NIHR Imperial Biomedical Research Centre Funding Scheme. E G A M is supported by the Imperial College Healthcare Charity Fellowship. W S D is funded by an NIHR Professorship. A N C is supported by the NIHR BRC and NHS. The views expressed are those of the authors and not necessarily those of the above-mentioned funders, the NHS, the NIHR or the Department of Health.

\section{References}

Abbara A, Jayasena CN, Christopoulos G, Narayanaswamy S, IzziEngbeaya C, Nijher GMK, Comninos AN, Peters D, Buckley A, Ratnasabapathy R, et al. 2015 Efficacy of kisspeptin-54 to trigger Oocyte maturation in women at high risk of ovarian 
hyperstimulation syndrome (OHSS) during in vitro fertilization (IVF) therapy. Journal of Clinical Endocrinology and Metabolism 100 3322-3331. (https://doi.org/10.1210/jc.2015-2332)

Adekunbi DA, Li XF, Lass G, Shetty K, Adegoke OA, Yeo SH, Colledge WH, Lightman SL \& O'Byrne KT 2018 Kisspeptin neurones in the posterodorsal medial amygdala modulate sexual partner preference and anxiety in male mice. Journal of Neuroendocrinology 30 e12572. (https://doi.org/10.1111/jne.12572)

Asaba A, Osakada T, Touhara K, Kato M, Mogi K \& Kikusui T 2017 Male mice ultrasonic vocalizations enhance female sexual approach and hypothalamic kisspeptin neuron activity. Hormones and Behavior 94 53-60. (https://doi.org/10.1016/j.yhbeh.2017.06.006)

Bakker J, Pierman S \& González-Martínez D 2010 Effects of aromatase mutation (ArKO) on the sexual differentiation of kisspeptin neuronal numbers and their activation by same versus opposite sex urinary pheromones. Hormones and Behavior 57 390-395. (https://doi. org/10.1016/j.yhbeh.2009.11.005)

Carter JN, Tyson JE, Tolis G, Van Vliet S, Faiman C \& Friesen HG 1978 Prolactin-secreting tumors and hypogonadism in 22 men. New England Journal of Medicine 299 847-852. (https://doi.org/10.1056/ NEJM197810192991602)

Chen CV, Brummet JL, Lonstein JS, Jordan CL \& Breedlove SM 2014 New knockout model confirms a role for androgen receptors in regulating anxiety-like behaviors and HPA response in mice. Hormones and Behavior 65 211-218. (https://doi.org/10.1016/j.yhbeh.2014.01.001)

Clarkson J \& Herbison AE 2006 Postnatal development of kisspeptin neurons in mouse hypothalamus; sexual dimorphism and projections to gonadotropin-releasing hormone neurons. Endocrinology 147 5817-5825. (https://doi.org/10.1210/en.2006-0787)

Clarkson J, d'Anglemont de Tassigny X, Colledge WH, Caraty A \& Herbison AE 2009 Distribution of kisspeptin neurones in the adult female mouse brain. Journal of Neuroendocrinology 21 673-682. (https://doi.org/10.1111/j.1365-2826.2009.01892.x)

Clarkson J, Han SY, Piet R, McLennan T, Kane GM, Ng J, Porteous RW, Kim JS, Colledge WH, Iremonger KJ, et al. 2017 Definition of the hypothalamic GnRH pulse generator in mice. PNAS 114 E10216-E10223. (https://doi.org/10.1073/pnas.1713897114)

Clements MK, McDonald TP, Wang R, Xie G, O’Dowd BF, George SR, Austin CP \& Liu Q 2001 FMRFamide-related neuropeptides are agonists of the orphan G-protein-coupled receptor GPR54. Biochemical and Biophysical Research Communications 284 1189-1193. (https://doi. org/10.1006/bbrc.2001.5098)

Comninos A \& Dhillo WS 2017 Emerging roles of kisspeptin in sexual and emotional brain processing. Neuroendocrinology 106 195-202. (https://doi.org/10.1159/000481137)

Comninos AN, Anastasovska J, Sahuri-Arisoylu M, Li X, Li S, Hu M, Jayasena CN, Ghatei MA, Bloom SR, Matthews PM, et al. 2016 Kisspeptin signaling in the amygdala modulates reproductive hormone secretion. Brain Structure and Function $2212035-2047$. (https://doi.org/10.1007/s00429-015-1024-9)

Comninos AN, Wall MB, Demetriou L, Shah AJ, Clarke SA, Narayanaswamy S, Nesbitt A, Izzi-Engbeaya C, Prague JK, Abbara A, et al. 2017 Kisspeptin modulates sexual and emotional brain processing in humans. Journal of Clinical Investigation 127 709-719. (https://doi.org/10.1172/JCI89519)

Cooke BM, Tabibnia G \& Breedlove SM 1999 A brain sexual dimorphism controlled by adult circulating androgens. PNAS 96 7538-7540. (https://doi.org/10.1073/pnas.96.13.7538)

Corona G, Isidori AM, Buvat J, Aversa A, Rastrelli G, Hackett G, Rochira V, Sforza A, Lenzi A, Mannucci E, et al. 2014 Testosterone supplementation and sexual function: a meta-analysis study. Journal of Sexual Medicine 11 1577-1592. (https://doi.org/10.1111/jsm.12536)

Csabafi K, Jászberényi M, Bagosi Z, Lipták N \& Telegdy G 2013 Effects of kisspeptin-13 on the hypothalamic-pituitary-adrenal axis, thermoregulation, anxiety and locomotor activity in rats. Behavioural Brain Research 241 56-61. (https://doi.org/10.1016/j.bbr.2012.11.039) de Roux N, Genin E, Carel J-C, Matsuda F, Chaussain J-L \& Milgrom E 2003 Hypogonadotropic hypogonadism due to loss of function of the KiSS1-derived peptide receptor GPR54. PNAS 100 10972-10976. (https://doi.org/10.1073/pnas.1834399100)

De Tassigny XDA, Fagg LA, Carlton MBL \& Colledge WH 2008 Kisspeptin can stimulate Gonadotropin-Releasing Hormone (GnRH) release by a direct action at GnRH nerve terminals. Endocrinology 149 3926-3932. (https://doi.org/10.1210/en.2007-1487)

Delmas S, Porteous R, Bergin DH \& Herbison AE 2018 Altered aspects of anxiety-related behavior in kisspeptin receptor-deleted male mice. Scientific Reports 8 2794. (https://doi.org/10.1038/s41598-018-210424)

Dhillo WS, Chaudhri OB, Patterson M, Thompson EL, Murphy KG, Badman MK, McGowan BM, Amber V, Patel S, Ghatei MA, et al. 2005 Kisspeptin-54 stimulates the hypothalamic-pituitary gonadal axis in human males. Journal of Clinical Endocrinology and Metabolism 90 6609-6615. (https://doi.org/10.1210/jc.2005-1468)

Dulac C \& Torello AT 2003 Molecular detection of pheromone signals in mammals: from genes to behaviour. Nature Reviews Neuroscience 4 551-562. (https://doi.org/10.1038/nrn1140)

Gaytán F, Gaytán M, Castellano JM, Romero M, Roa J, Aparicio B, Garrido N, Sánchez-Criado JE, Millar RP, Pellicer A, et al. 2009 KiSS-1 in the mammalian ovary: distribution of kisspeptin in human and marmoset and alterations in KiSS-1 mRNA levels in a rat model of ovulatory dysfunction. American Journal of Physiology: Endocrinology and Metabolism 296 E520-E531. (https://doi.org/10.1152/ ajpendo.90895.2008)

Gottsch ML, Cunningham MJ, Smith JT, Popa SM, Acohido BV, Crowley WF, Seminara S, Clifton DK \& Steiner RA 2004 A role for kisspeptins in the regulation of gonadotropin secretion in the mouse. Endocrinology 145 4073-4077. (https://doi.org/10.1210/en.2004-0431)

Gottsch ML, Clifton DK \& Steiner RA 2009 From KISS1 to kisspeptins: an historical perspective and suggested nomenclature. Peptides 30 4-9. (https://doi.org/10.1016/j.peptides.2008.06.016)

Gresham R, Li S, Adekunbi DA, Hu M, Li XF \& TO’Byrne K 2016 Kisspeptin in the medial amygdala and sexual behavior in male rats. Neuroscience Letters 627 13-17. (https://doi.org/10.1016/j. neulet.2016.05.042)

Han S-K 2005 Activation of gonadotropin-releasing hormone neurons by kisspeptin as a neuroendocrine switch for the onset of puberty. Journal of Neuroscience 25 11349-11356. (https://doi.org/10.1523/ JNEUROSCI.3328-05.2005)

Hanchate NK, Parkash J, Bellefontaine N, Mazur D, Colledge WH, d'Anglemont de Tassigny X \& Prevot V 2012 Kisspeptin-GPR54 signaling in mouse NO-synthesizing neurons participates in the hypothalamic control of ovulation. Journal of Neuroscience $\mathbf{3 2}$ 932-945. (https://doi.org/10.1523/JNEUROSCI.4765-11.2012)

Hellier V, Brock O, Candlish M, Desroziers E, Aoki M, Mayer C, Piet R, Herbison A, Colledge WH, Prévot V, et al. 2018 Female sexual behavior in mice is controlled by kisspeptin neurons. Nature Communications 9 400. (https://doi.org/10.1038/s41467-017-02797-2)

Herbison AE, De Tassigny XDA, Doran J \& Colledge WH 2010 Distribution and postnatal development of Gpr54 gene expression in mouse brain and gonadotropin-releasing hormone neurons. Endocrinology 151 312-321. (https://doi.org/10.1210/en.2009-0552)

Hrabovszky E 2014 Neuroanatomy of the human hypothalamic kisspeptin system. Neuroendocrinology 99 33-48. (https://doi. org/10.1159/000356903)

Hrabovszky E, Ciofi P, Vida B, Horvath MC, Keller E, Caraty A, Bloom SR, Ghatei MA, Dhillo WS, Liposits Z, et al. 2010 The kisspeptin system of the human hypothalamus: sexual dimorphism and relationship with gonadotropin-releasing hormone and neurokinin B neurons. European Journal of Neuroscience 31 1984-1998. (https://doi.org/10.1111/j.14609568.2010.07239.x)

Hull EM, Wood RI \& McKenna KE 2006 Neurobiology of male sexual behavior. In Knobil and Neill's Physiology of Reproduction, pp 1729-1824.
(C) 2018 Society for Endocrinology Published by Bioscientifica Ltd. Printed in Great Britain 
San Diego, CA, USA: Elsevier. (https://doi.org/10.1016/B978012515400-0/50038-5)

Jayasena CN, Nijher GMK, Chaudhri OB, Murphy KG, Ranger A, Lim A, Patel D, Mehta A, Todd C, Ramachandran R, et al. 2009 Subcutaneous injection of kisspeptin-54 acutely stimulates gonadotropin secretion in women with hypothalamic amenorrhea, but chronic administration causes tachyphylaxis. Journal of Clinical Endocrinology and Metabolism 94 4315-4323. (https://doi.org/10.1210/jc.2009-0406)

Jayasena CN, Nijher GMK, Abbara A, Murphy KG, Lim A, Patel D, Mehta A, Todd C, Donaldson M, Trew GH, et al. 2010 Twice-weekly administration of kisspeptin-54 for 8 weeks stimulates release of reproductive hormones in women with hypothalamic amenorrhea. Clinical Pharmacology and Therapeutics 88 840-847. (https://doi. org/10.1038/clpt.2010.204)

Jayasena CN, Abbara A, Veldhuis JD, Comninos AN, Ratnasabapathy R, De Silva A, Nijher GMK, Ganiyu-Dada Z, Mehta A, Todd C, et al. $2014 a$ Increasing LH pulsatility in women with hypothalamic amenorrhoea using intravenous infusion of kisspeptin-54. Journal of Clinical Endocrinology and Metabolism 99 E953-E961. (https://doi. org/10.1210/jc.2013-1569)

Jayasena CN, Abbara A, Comninos AN, Nijher GMK, Christopoulos G, Narayanaswamy S, Izzi-Engbeaya C, Sridharan M, Mason AJ, Warwick J, et al. $2014 b$ Kisspeptin-54 triggers egg maturation in women undergoing in vitro fertilization. Journal of Clinical Investigation 124 3667-3677. (https://doi.org/10.1172/JCI75730)

Kauffman AS, Park JH, McPhie-Lalmansingh AA, Gottsch ML, Bodo C, Hohmann JG, Pavlova MN, Rohde AD, Clifton DK, Steiner RA, et al. 2007 The kisspeptin receptor GPR54 is required for sexual differentiation of the brain and behavior. Journal of Neuroscience $\mathbf{2 7}$ 8826-8835. (https://doi.org/10.1523/JNEUROSCI.2099-07.2007)

Kim J, Semaan SJ, Clifton DK, Steiner RA, Dhamija S \& Kauffman AS 2011 Regulation of Kiss1 expression by sex steroids in the amygdala of the rat and mouse. Endocrinology 152 2020-2030. (https://doi. org/10.1210/en.2010-1498)

Kinsey-Jones JS, Li XF, Knox AMI, Wilkinson ES, Zhu XL, Chaudhary AA, Milligan SR, Lightman SL \& O'Byrne KT 2009 Down-regulation of hypothalamic Kisspeptin and its receptor, Kiss1r, mRNA expression is associated with stress-induced suppression of luteinising hormone secretion in the female rat. Journal of Neuroendocrinology 21 20-29. (https://doi.org/10.1111/j.1365-2826.2008.01807.x)

Kitahashi T, Ogawa S \& Parhar IS 2009 Cloning and expression of kiss2 in the zebrafish and medaka. Endocrinology 150 821-831. (https://doi. org/10.1210/en.2008-0940)

Kongsted AG 2004 Stress and fear as possible mediators of reproduction problems in group housed sows: a review. Acta Agriculturae Scandinavica, Section A: Animal Science 54 58-66. (https://doi. org/10.1080/09064700410032031)

Kotani M, Detheux M, Vandenbogaerde A, Communi D, Vanderwinden JM, Le Poul E, Brézillon S, Tyldesley R, SuarezHuerta N, Vandeput F, et al. 2001 The metastasis suppressor gene KiSS-1 encodes kisspeptins, the natural ligands of the orphan G protein-coupled receptor GPR54. Journal of Biological Chemistry 276 34631-34636. (https://doi.org/10.1074/jbc.M104847200)

Kow LM, Florea C, Schwanzel-Fukuda M, Devidze N, Kami Kia H, Lee A, Zhou J, MacLaughlin D, Donahoe P \& Pfaff D 2007 Development of a sexually differentiated behavior and its underlying CNS arousal functions. Current Topics in Developmental Biology 79 37-59. (https:// doi.org/10.1016/S0070-2153(06)79002-0)

Lakatos E, Szigeti JF, Ujma PP, Sexty R \& Balog P 2017 Anxiety and depression among infertile women: a cross-sectional survey from Hungary. BMC Women's Health 17 48. (https://doi.org/10.1186/ s12905-017-0410-2)

Lee JH, Miele ME, Hicks DJ, Phillips KK, Trent JM, Weissman BE \& Welch DR 1996 KiSS-1, a novel human malignant melanoma metastasis-suppressor gene. Journal of the National Cancer Institute $\mathbf{8 8}$ 1731-1737. (https://doi.org/10.1093/jnci/88.23.1731)
Lee DK, Nguyen T, O’Neill GP, Cheng R, Liu Y, Howard AD, Coulombe N, Tan CP, Tang-Nguyen AT, George SR, et al. 1999 Discovery of a receptor related to the galanin receptors. FEBS Letters 446 103-107. (https://doi.org/10.1016/S0014-5793(99)00009-5)

Lehman MN, Winans SS \& Powers JB 1980 Medial nucleus of the amygdala mediates chemosensory control of male hamster sexual behavior. Science 210 557-560. (https://doi.org/10.1126/ science.7423209)

Lehman MN, Coolen LM, Steiner RA, Neal-Perry G, Wang L, Moenter SM, Moore AM, Goodman RL, Hwa-Yeo S, Padilla SL, et al. 2018 The 3rd World Conference on Kisspeptin, 'Kisspeptin 2017: Brain and Beyond': unresolved questions, challenges and future directions for the field. Journal of Neuroendocrinology 30 e12600. (https://doi. org/10.1111/jne.12600)

Lindenfors P \& Tullberg BS 2011 Evolutionary aspects of aggression: the importance of sexual selection. Advances in Genetics 75 7-22. (https:// doi.org/10.1016/B978-0-12-380858-5.00009-5)

Liu X \& Herbison A 2015 Kisspeptin regulation of arcuate neuron excitability in kisspeptin receptor knockout mice. Endocrinology 156 1815-1827. (https://doi.org/10.1210/en.2014-1845)

MacLean DB, Matsui H, Suri A, Neuwirth R \& Colombel M 2014 Sustained exposure to the investigational kisspeptin analog, TAK-448, down-regulates testosterone into the castration range in healthy males and in patients with prostate cancer: results from two phase 1 studies. Journal of Clinical Endocrinology and Metabolism 99 E1445-E1453. (https://doi.org/10.1210/jc.2013-4236)

Mason AO, Greives TJ, Scotti MAL, Levine J, Frommeyer S, Ketterson ED Demas GE \& Kriegsfeld LJ 2007 Suppression of kisspeptin expression and gonadotropic axis sensitivity following exposure to inhibitory day lengths in female Siberian hamsters. Hormones and Behavior $\mathbf{5 2}$ 492-498. (https://doi.org/10.1016/j.yhbeh.2007.07.004)

Matsui H, Masaki T, Akinaga Y, Kiba A, Takatsu Y, Nakata D, Tanaka A, Ban J, Matsumoto SI, Kumano S, et al. 2014 Pharmacologic profiles of investigational kisspeptin/metastin analogues, TAK-448 and TAK-683, in adult male rats in comparison to the GnRH analogue leuprolide. European Journal of Pharmacology 735 77-85. (https://doi. org/10.1016/j.ejphar.2014.03.058)

Meisami E \& Bhatnagar KP 1998 Structure and diversity in mammalian accessory olfactory bulb. Microscopy Research and Technique 43 476-499. (https://doi.org/10.1002/(SICI)10970029(19981215)43:6<476::AID-JEMT2<3.0.CO;2-V)

Messager S, Chatzidaki EE, Ma D, Hendrick AG, Zahn D, Dixon J, Thresher RR, Malinge I, Lomet D, Carlton MBL, et al. 2005 Kisspeptin directly stimulates gonadotropin-releasing hormone release via $\mathrm{G}$ protein-coupled receptor 54. PNAS 102 1761-1766. (https://doi. org/10.1073/pnas.0409330102)

Messina A, Langlet F, Chachlaki K, Roa J, Rasika S, Jouy N, Gallet S, Gaytan F, Parkash J, Tena-Sempere M, et al. 2016 A microRNA switch regulates the rise in hypothalamic GnRH production before puberty. Nature Neuroscience 19 835. (https://doi.org/10.1038/nn.4298)

Meyer-Lindenberg A, Domes G, Kirsch P \& Heinrichs M 2011 Oxytocin and vasopressin in the human brain: social neuropeptides for translational medicine. Nature Reviews Neuroscience 12 524-538. (https://doi.org/10.1038/nrn3044)

Mikkelsen JD \& Simonneaux V 2009 The neuroanatomy of the kisspeptin system in the mammalian brain. Peptides 30 26-33. (https://doi. org/10.1016/j.peptides.2008.09.004)

Muir AI, Chamberlain L, Elshourbagy NA, Michalovich D, Moore DJ, Calamari A, Szekeres PG, Sarau HM, Chambers JK, Murdock P, et al. 2001 AXOR12, a novel human G protein-coupled receptor, activated by the peptide KiSS-1. Journal of Biological Chemistry 276 28969-28975. (https://doi.org/10.1074/jbc.M102743200)

Murray EA 2007 The amygdala, reward and emotion. Trends in Cognitive Sciences 11 489-497. (https://doi.org/10.1016/j.tics.2007.08.013)

Nathan FM, Ogawa S \& Parhar IS 2015 Kisspeptin1 modulates odorantevoked fear response via two serotonin receptor subtypes $\left(5-\mathrm{HT}_{1 \mathrm{~A}}\right.$ and 
5-HT ${ }_{2}$ ) in zebrafish. Journal of Neurochemistry 133 870-878. (https:// doi.org/10.1111/jnc.13105)

Neuman-Lee L, Grieves T, Hopkins GR \& French SS 2017 The role of the kisspeptin system in regulation of the reproductive endocrine axis and territorial behavior in male side-blotched lizards (Uta stansburiana). Hormones and Behavior 89 48-54. (https://doi. org/10.1016/j.yhbeh.2016.12.006)

Ogawa S, Nathan FM \& Parhar IS 2014 Habenular kisspeptin modulates fear in the zebrafish. PNAS 111 3841-3846. (https://doi.org/10.1073/ pnas.1314184111)

Ohtaki T, Shintani Y, Honda S, Matsumoto H, Hori A, Kanehashi K, Terao Y, Kumano S, Takatsu Y, Masuda Y, et al. 2001 Metastasis suppressor gene KiSS-1 encodes peptide ligand of a G-protein-coupled receptor. Nature $\mathbf{4 1 1}$ 613-617. (https://doi.org/10.1038/35079135)

Pineda R, Plaisier F, Millar RP \& Ludwig M 2017 Amygdala kisspeptin neurons: putative mediators of olfactory control of the gonadotropic axis. Neuroendocrinology 104 223-238. (https://doi. org/10.1159/000445895)

Ramasamy R, Wilken N, Scovell JM \& Lipshultz LI 2015 Effect of testosterone supplementation on symptoms in men with hypogonadism. European Urology 67 176-177. (https://doi. org/10.1016/j.eururo.2014.08.048)

Rao YS, Mott NN \& Pak TR 2011 Effects of kisspeptin on parameters of the HPA axis. Endocrine 39 220-228. (https://doi.org/10.1007/s12020011-9439-4)

Rometo AM, Krajewski SJ, Lou Voytko M \& Rance NE 2007 Hypertrophy and increased kisspeptin gene expression in the hypothalamic infundibular nucleus of postmenopausal women and ovariectomized monkeys. Journal of Clinical Endocrinology and Metabolism 92 2744-2750. (https://doi.org/10.1210/jc.2007-0553)

Seminara SB, Messager S, Chatzidaki EE, Thresher RR, Acierno JS, Shagoury JK, Bo-Abbas Y, Kuohung W, Schwinof KM, Hendrick AG, et al. 2003 The GPR54 gene as a regulator of puberty. New England Journal of Medicine 349 1614-1627. (https://doi.org/10.1056/ NEJMoa035322)

Sonigo C, Bouilly J, Carré N, Tolle V, Caraty A, Tello J, Simony-Conesa FJ, Millar R, Young J \& Binart N 2012 Hyperprolactinemia-induced ovarian acyclicity is reversed by kisspeptin administration. Journal of Clinical Investigation 122 3791-3795. (https://doi.org/10.1172/ JCI63937)

Tanaka M, Csabafi K \& Telegdy G 2013 Neurotransmissions of antidepressant-like effects of kisspeptin-13. Regulatory Peptides 180 1-4. (https://doi.org/10.1016/j.regpep.2012.08.017)

Teles MG, Bianco SDC, Brito VN, Trarbach EB, Kuohung W, Xu S, Seminara SB, Mendonca BB, Kaiser UB \& Latronico AC 2008 A GPR54activating mutation in a patient with central precocious puberty. New England Journal of Medicine 358 709-715. (https://doi.org/10.1056/ NEJMoa073443)

Tena-Sempere M, Felip A, Gómez A, Zanuy S \& Carrillo M 2012 Comparative insights of the kisspeptin/kisspeptin receptor system: lessons from non-mammalian vertebrates. General and Comparative Endocrinology 175 234-243. (https://doi.org/10.1016/j. ygcen.2011.11.015)

Thomson EL, Patterson M, Murphy KG, Smith KL, Dhillo WS, Todd JF, Ghatei MA \& Bloom SR 2004 Central and peripheral administration of kisspeptin-10 stimulates the hypothalamic-pituitary-gonadal axis. Journal of Neuroendocrinology 16 850-858. (https://doi.org/10.1111/ j.1365-2826.2004.01240.x)

Topalglu AK, Tello JA, Kotan LD, Ozbek MN, Yilmaz MB, Erdogan S, Gurbuz F, Temiz F, Millar RP \& Yuksel B 2012 Inactivating KISS1 mutation and hypogonadotropic hypogonadism. Obstetrical and Gynecological Survey 67 352-353. (https://doi.org/10.1097/ OGX.0b013e31825bc1be)

Vandenbergh JG 2006 Pheromones and mammalian reproduction. In Knobil and Neill's Physiology of Reproduction, pp 2041-2058. San Diego, CA, USA: Elsevier. (https://doi.org/10.1016/B978-0125154000/50042-7)

Watanabe Y, Ikegami K, Ishigaki R, Ieda N, Uenoyama Y, Maeda KI, Tsukamura H \& Inoue N 2017 Enhancement of the luteinising hormone surge by male olfactory signals is associated with anteroventral periventricular Kiss1 cell activation in female rats. Journal of Neuroendocrinology 29 e12505. (https://doi.org/10.1111/ jne.12505)

Yang L, Comninos AN \& Dhillo WS 2018 Intrinsic links among sex, emotion, and reproduction. Cellular and Molecular Life Sciences 752197-2210. (https://doi.org/10.1007/s00018-018-2802-3)

Received in final form 18 June 2018

Accepted 2 July 2018

Accepted Preprint published online 2 July 2018 (c) 2018 Society for Endocrinology Published by Bioscientifica Ltd. Printed in Great Britain 